\title{
SISTEMA DE AVALIAÇÃO DA GESTÃO DE ESTOQUES EM UMA EMPRESA DO SETOR ELÉTRICO NO ESTADO DO PARÁ
}

\section{EVALUATION SYSTEM OF INVENTORY MANAGEMENT IN A COMPANY OF ELECTRICITY SECTOR IN THE STATE OF PARA}

\author{
Nayáry Pinheiro Monteiro ${ }^{1}$; André Cristiano Silva $\mathrm{Melo}^{2}$; Denilson Ricardo de Lucena Nunes ${ }^{3}$ \\ ${ }^{1}$ Universidade do Estado do Pará - UEPA - Belém, Pa; Brasil, Engenheira de produção. \\ narypinheiro@gmail.com \\ ${ }^{2}$ Universidade do Estado do Pará - UEPA - Belém, Pa; Brasil, Prof. D.Sc. \\ acsmelo@yahoo.com.br \\ ${ }^{3}$ Universidade do Estado do Pará - UEPA - Belém, Pa; Brasil, Prof. D.Sc. \\ denilson.lucena@ibest.com.br
}

\begin{abstract}
Resumo
Este artigo apresenta uma metodologia para elaboração de um Sistema de Avaliação de Desempenho da Gestão de Estoques baseado em indicadores logísticos. Para tanto, foi elaborado um projeto piloto a ser aplicado no almoxarifado central de uma empresa do setor elétrico, localizada no Estado do Pará. A definição dos indicadores de desempenho para essa situação foi realizada a partir do mapeamento dos processos de produção e posterior identificação dos processos críticos, mediante a visão estratégica da empresa. Em seguida, foram definidos os itens de estoque para o projeto piloto, que se baseou em uma ferramenta computacional destinada a coleta e tratamento automático dos dados, bem como a visualização dos indicadores de desempenho. A partir dos primeiros resultados obtidos, foi possível mensurar o desempenho dos processos do almoxarifado considerando os indicadores a serem melhorados. Assim, tornou-se evidente o potencial de uso do sistema proposto na melhoria contínua das atividades de Gestão de Estoque.
\end{abstract}

Palavras-chave: indicadores de desempenho; administração de materiais; gestão de estoques; setor elétrico.

\section{Introdução}

A importância do suprimento energético é relevante, pois a energia está entre os principais indicadores que definem o grau de desenvolvimento de uma nação, e segundo a Agência Nacional de Energia Elétrica (2008), o setor elétrico mundial está em franca evolução, em especial no Brasil. Além disso, de acordo com o Plano Decenal de Expansão de Energia 2020 (2011), a capacidade instalada do parque gerador de energia elétrica deverá crescer $56 \%$ na próxima década, representando um aumento aproximado de 6 mil megawatts anuais e uma resposta ao crescimento da demanda energética do país. Em relação ao Pará, grande parte da energia elétrica consumida é gerada pelas usinas hidrelétricas Tucuruí e Curuá-Uma, portanto, faz-se necessário um sistema de 
apoio que garanta o pleno funcionamento dessa rede, por se tratar de uma atividade base para outros setores (industriais, agrícolas etc.), bem como o fornecimento contínuo e confiável, com baixa tolerância a falhas.

A garantia de um fornecimento contínuo e confiável tem relação direta com as atividades logísticas, que atuam como suporte a todos os processos que compõem essa cadeia de suprimentos na produção de energia elétrica. Uma vez que o desempenho logístico passou a ter um enfoque estratégico pelas empresas, sendo hoje um dos elementos-chave na estratégia competitiva das organizações, surge então a necessidade de um Sistema de Avaliação de Desempenho (SAD) que acompanhe a execução das atividades logísticas através de indicadores (Supply Chain Management - SCM) (NOVAES, 2007).

Dessa forma, este artigo apresenta uma proposta de SAD aplicado à gestão de estoques de uma empresa do setor elétrico localizada no Estado do Pará. Para tal, foram definidos indicadores logísticos de desempenho de acordo com as necessidades da empresa, com o mapeamento dos processos e a identificação dos pontos críticos de controle para a gestão. Em seguida, para alguns materiais utilizados, foi desenvolvida uma ferramenta computacional que tem por objetivo tratar e visualizar informações desses materiais obtidas a partir do banco de dados da empresa. Como resultado, foi possível mensurar o desempenho dos processos do almoxarifado, bem como identificar possibilidades de melhorias. Portanto, a ferramenta proposta consistiu um elemento importante no processo de melhoria contínua das atividades de Administração de Materiais desenvolvidas na empresa.

Assim, o texto deste artigo foi organizado da seguinte forma: a Seção 2 contém um levantamento bibliográfico, referente à Avaliação e Indicadores de Desempenho, e à Logística do Setor Elétrico, no sentido de identificar as possíveis relações entre esses temas e, assim, justificar a importância da proposta de SAD, formalizada neste artigo. Na Seção 3 são encontrados detalhes do projeto piloto do SAD para gestão de estoques, implementado em uma empresa do setor elétrico, atuante na geração e transmissão de energia no estado do Pará. Na Seção 4 são analisados os primeiros resultados obtidos com a implementação dessa proposta na empresa objeto de estudo. Ao final do texto na Seção 5 foram reunidas as considerações sobre os resultados obtidos e apresenta propostas adicionais de pesquisas futuras.

\section{Revisão bibliográfica}

\subsection{Avaliação de desempenho}

De acordo com Davis, Aquilano e Chase (2001), a capacidade de mensurar o desempenho é essencial para dar um norte ao sistema de gestão, pois sem as informações provenientes da apuração 
dos resultados do sistema, os gerentes não conseguem avaliar a performance da organização ou compará-la com a dos demais concorrentes.

A avaliação de desempenho se concretiza como um processo quando existe uma estrutura responsável por: coletar os dados; estabelecer os parâmetros; e apresentar os resultados. Nessa linha destaca-se o conceito de Sistemas de Medição de Desempenho (SMD), que reúnem um conjunto de métricas usadas para quantificar a eficiência das ações.

Segundo a visão de Martins (1998) apud Lima (2008), existem aspectos essenciais que devem caracterizar um SMD efetivo, dentre eles pode-se destacar: congruência com a estratégia competitiva; possuir medidas financeiras e não financeiras; identificar tendências e progressos; direcionar e suportar melhoria; facilitar o entendimento de relações de causa e efeito; ser facilmente inteligível aos funcionários; abranger a totalidade dos processos em cadeia (do fornecedor ao cliente); estar disponível em tempo real para toda organização; ser dinâmico; influenciar nas atitudes dos funcionários e avaliar o grupo e não o indivíduo. Conforme aumenta a complexidade das organizações, maior torna-se a necessidade e a importância da existência de um sistema de indicadores inter-relacionados.

Os componentes de desempenho logístico, segundo Melo (2011), são classificados segundo seu nível de planejamento como: operacionais (estoques, instalações, transporte e informações) e estratégicos (custos e nível de serviço). Desses componentes apenas os operacionais são de interesse deste artigo. Para Moreira (2009), estoques podem ser definidos como qualquer quantidade de bens físicos que sejam conservados, de forma improdutiva por algum período. Nesse sentido, o grande dilema dos estoques consiste em manter o maior nível de serviço possível com o menor percentual de custos.

Segundo Ballou (2001), instalações podem ser definidas como pontos na rede logística por onde passam fluxos de produtos, que podem ficar parados temporariamente, podem ser transformados ou podem somente transitar até chegarem ao seu destino. Para Chiavenato (2005), a escolha de um local para situar as instalações depende de vários fatores que devem ser analisados em conjunto adequadamente, como: Disponibilidade de mão de obra; Proximidade das fontes de matéria - prima ou de fornecedores; Proximidade aos mercados consumidores; Facilidade de transporte ou acesso a estradas, ferrovias etc.; Infraestrutura; Tamanho da instalação; Incentivos fiscais.

Por fim, para Bertaglia (2009), o processo inteiro de movimentação física (ou fluxo) de materiais e produtos possui relação direta com um fluxo de informações. Desde o processamento de pedido na entrada dos insumos, passando pelo planejamento, armazenagem e outras etapas, até sua entrega final, existe uma rede de informações que dá suporte para que tudo aconteça. Os sistemas de informação possuem as funções de iniciar as atividades e rastrear as informações sobre os 
processos, facilitar o compartilhamento das informações e embasar à tomada de decisão gerencial (BOWERSOX, CLOSS, COOPER, 2007).

O pleno entendimento desses fluxos permite identificar o que realmente agrega valor ao processo, o que dá base para o descarte daquilo que não agregue, aumentando a confiabilidade e a rapidez das transações (BERTAGLIA, 2009).

\subsection{Indicadores de desempenho}

A Fundação Nacional da Qualidade - FNQ (2008) afirma que os indicadores de desempenho podem ser entendidos como os elementos que quantificam os inputs (recursos ou insumos), os processos, os outputs (produtos), o desempenho de fornecedores e a satisfação das partes interessadas. Apesar da existência de um crescente número de indicadores de desempenho disponíveis, segundo Davis, Aquilano e Chase (2001), os gestores devem ser seletivos na escolha daqueles que são realmente críticos e que mais se adéquam à realidade da sua empresa, pois muitas organizações se equivocam ao adotar a avaliação de desempenho de forma aleatória e impensada e acabam por desacreditar na efetividade do sistema.

Quanto as suas funções, Silva (2007), aborda quatro funções básicas dos indicadores: medir e analisar o desempenho dos processos e produtos orientados para as necessidades dos clientes sejam eles internos ou externos; possibilitar o estabelecimento e desdobramento das metas organizacionais; analisar criticamente os resultados dos processos e permitir a tomada de decisão; e verificar a efetividade (eficiência e eficácia) dos processos organizacionais.

Quanto à classificação, Kaplan e Norton, (2007); Bowersox, Closs e Cooper (2007); Gunasekaran, Patel e Tirtiroglu (2001), concordam que os indicadores de desempenho podem ser divididos em: a) Quanto à natureza em financeiros e não financeiros; b) Quanto ao tipo de foco em funcionais ou de processos; c) Quanto ao grau de relação com aspectos extrínsecos à organização em indicadores internos ou externos; d) Quanto ao posicionamento no nível de planejamento em indicadores estratégicos, táticos ou operacionais.

De acordo com Rentes, Carpinetti e Aken (2002), existe uma sistemática para implementação de um sistema de avaliação de desempenho, conforme ilustrado na Figura 1. São etapas sequenciadas que foram estabelecidas para servir como um guia e, por serem amplas, podem ser utilizadas em qualquer tipo de organização e para qualquer área de análise. Dentro dessa sistemática, é essencial a definição e o detalhamento dos indicadores que serão utilizados. Além disso, a definição correta dos indicadores garante a redução de confusões na interpretação dos dados e influencia no próprio processo de criação das medidas. 
Segundo Jacobsen (2006), os principais indicadores conhecidos na literatura para gestão de estoques, são: giro de estoques, cobertura de estoques, nível de serviço e o retorno de capital investido em estoques. As formulações são encontradas no Quadro 1.

Figura 1 - Passos para o desenvolvimento de um SMD

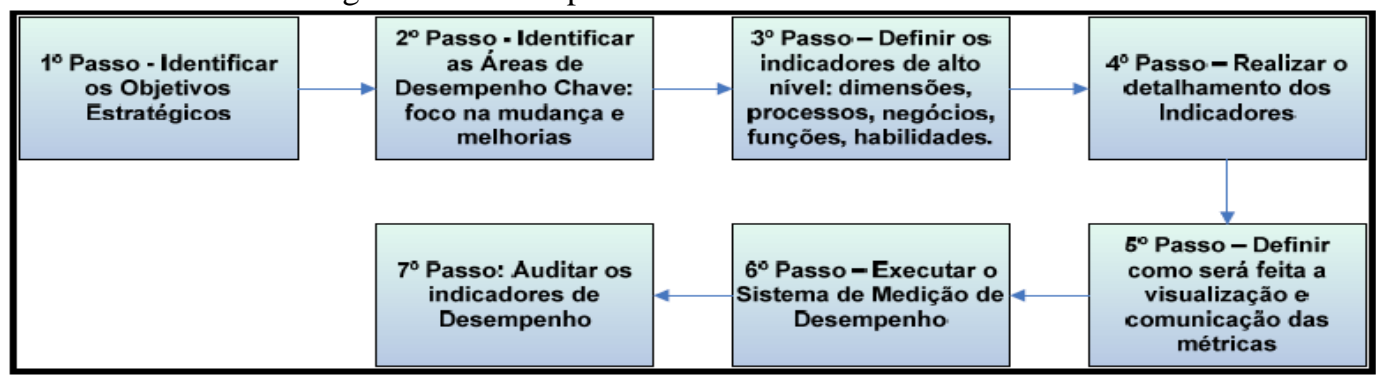

Fonte: Adaptado de Rentes, Carpinetti e Aken (2002).

Quadro 1 - Indicadores para a gestão de estoques

\begin{tabular}{c} 
Giro Anal $=\frac{\text { Demanda Anual }}{\text { Estoque médio }}$ \\
Cobertura $=\frac{\frac{360 \text { dias }}{\text { ano }} \text { Xalor do Estoque Médio }}{\text { Valor da Demanda Anual }}$ \\
\hline Nível de Serviço $=\frac{\text { Quantidade de códigos ativos com saldo } \neq \text { zero } \times 100}{\text { Quantidade de códigos ativos }}$ \\
\hline Retorno do Capital Investido $=\frac{\text { Lucro de vendas }}{\text { Capital Investido em Estoques }}$ \\
\hline Número de itens com resgistros corretos \\
Número total de itens
\end{tabular}

Fonte: Autores

Cada um desses indicadores possui interpretação própria. O Giro de estoque representa quantas vezes em determinado intervalo de tempo o estoque se renovou (MARTINS e ALT, 2009). A Cobertura de Estoque indica o tempo de consumo total dos estoques, sendo que essa análise pode ser feita sobre o estoque real ou o estoque médio. O Nível de Serviço é definido por Jacobsen (2006) como a relação entre a quantidade atendida e a quantidade solicitada pelos clientes, sendo utilizado pala avaliação do grau de disponibilidade do serviço. O retorno do capital investido em estoque representa quanto do capital imobilizado no estoque (C) retorna na forma de lucro (L). E por fim, Além dos índices apresentados acima, Martins e Alt (2009), aborda a importância da avaliação da acuracidade dos estoques, que representa o percentual de itens com quantidades e valores corretos em relação ao sistema de controle. 


\subsection{A logística do setor elétrico}

A cadeia produtiva do setor constitui-se basicamente de um ciclo integrado de três macrofunções: geração, transmissão e distribuição. O pleno funcionamento de cada um dessas funções é o que garante a qualidade do fornecimento energético ao consumidor final.

Essa cadeia produtiva possui configuração semelhante à de outras cadeias produtivas, com fornecedores, empresas, processos, saídas, concorrentes e clientes finais, além de uma série de diretrizes e normas que o regulamentam. Dentro dessa estrutura existe um conjunto de subsistemas logísticos. O principal subsistema refere-se a: projetos de configuração da rede; ampliação da capacidade total do sistema elétrico; decisões referentes a instalações (usinas e subestações); redes de transmissão e de distribuição de energia. Ou seja, diz respeito aos fluxos e atividades relacionadas ao escoamento do produto final (energia elétrica), desde sua geração até a distribuição ao consumidor final (MELO, 2006).

Além do Subsistema Principal, o Subsistema de Suporte garante que todos os recursos necessários ao pleno funcionamento das usinas de geração, das redes de transmissão e de distribuição estejam funcionando a contento, permitindo o fluxo contínuo da energia e a estabilidade do sistema elétrico. O Subsistema de Suporte pode ser conceituado como o subsistema responsável por atividades logísticas relacionadas à reposição de materiais e equipamentos, e à manutenção operacional do sistema elétrico. Sua atuação é indireta, mas ele garante às instalações do subsistema principal a disponibilidade de materiais, componentes elétricos e serviços (MELO, 2006). Nesse tipo de subsistema, fornecedores encarregados realizam todas as atividades de transporte de materiais, componentes, equipamentos e combustíveis até as instalações de armazenagem, de produção e ou de consumo.

No que tange o fornecimento de energia elétrica no Pará, a empresa objeto deste estudo é uma concessionária de serviço público de energia elétrica com alcance em nível nacional, apresentando, atualmente, uma potência total instalada de 9.294,33 MW e sistemas de transmissão que contam com mais de 9,888,02 Km de linhas, apresentando grande importância para região amazônica, pois beneficia aproximadamente $59 \%$ da população da mesma (DADOS DA EMPRESA, 2012). A empresa atua no Pará desde 1980 e, a partir de 1981, proporcionou ao Estado a participação no SIN, por meio da criação do ramal denominado Sistema Interligado Norte Nordeste. Este estudo foi realizado no almoxarifado de uma de suas unidades, a regional de transmissão do Estado do Pará.

Para garantir o fornecimento de energia elétrica em todo Estado, a Regional de Transmissão do Pará (localizada em Belém) conta com o apoio de quatro subestações descentralizadas, que estão localizadas em pontos estratégicos na região, são elas: Altamira, Vila do Conde, Marabá e Tucuruí. 
Cada uma dessas subestações possui um almoxarifado próprio e todos eles são abastecidos pelo almoxarifado central que está localizado em Belém.

O almoxarifado central possui grande relevância, pois, além de possuir as mesmas atribuições dos demais almoxarifados, ele é responsável tanto pelo por atividades como:

Planejamento de Estoque, Aquisição de bens e contratação de Obras e Serviços, Recebimento de Materiais no Almoxarifado, Armazenagem do Material, Movimentação de Material, Controle de Material no Almoxarifado e Alienação de Bens Patrimoniais Móveis.

\section{Aplicação da pesquisa no setor elétrico}

\subsection{Proposta de implementação do SAD}

A proposta de implantação do SAD foi iniciada a partir de um diagnóstico da atual gestão de estoque no Almoxarifado. Contatou-se que essa área da empresa apresenta dois pontos críticos para a melhoria de seu desempenho no que tange sua gestão de estoques. Os pontos identificados foram:

a) Subutilização das Informações, uma vez que a ferramenta operacional SAP/R3 utilizada pela empresa apresenta carências na consolidação das informações. O sistema é sobrecarregado de informações, mas, devido sua interface gráfica pouco flexível e pouco amigável, geralmente é utilizado para execução das rotinas e não para sua análise;

b) Ausência de avaliação do desempenho no almoxarifado, elemento que direciona o processo de melhoria contínua. Como consequência, nesse setor da empresa as decisões são dependentes do conhecimento tácito e experiência dos funcionários.

Portanto, nesse caso, a existência de indicadores de desempenho poderia trazer, entre outros benefícios para empresa: aumento do nível de atendimento e redução de estoques em excesso; visão sistêmica da gestão de materiais; melhoria do tempo de atendimento ao cliente; maior rapidez e eficiência na solução de problemas; redução do nível de incertezas; melhoria na qualidade de serviços; aperfeiçoamento do planejamento dos estoques; melhoria do controle nas relações com os fornecedores; possibilidade de certificação de qualidade no setor e redução do número de perdas e desperdícios, sendo esta última evidenciada no Quadro 2, onde são ilustradas as perdas referentes a materiais com prazo de validade vencido, visitado no dia 29/09/2011, constatando-se uma perda para a empresa em exatos $\mathrm{R} \$ 50.617,80$. 
Quadro 2 - Lista de materiais com prazo de validade vencido

\begin{tabular}{|c|c|c|c|c|c|c|}
\hline MATERIAL & \multirow{2}{*}{$\begin{array}{c}\text { QUANTIDADE } \\
40\end{array}$} & \multicolumn{3}{|c|}{ UND PRECO UNITARIO } & \multicolumn{2}{|c|}{ CUSTO TOTAL } \\
\hline ADESIVO RESINA EPOXI 10ML & & UN & RS & 7,61 & RS & 304,40 \\
\hline CARTUCHO TONER OKIDATA C5200N CIANO & 10 & UN & RS & 715,49 & RS & $7.154,90$ \\
\hline CARTUCHO TONER OKIDATA C5200N MAGENTA & 11 & UN & RS & 718,11 & RS & $7.899,21$ \\
\hline CARTUCHO TONER OKIDATA C5200N AMARELA & 4 & UN & RS & 721,54 & RS & $2.886,16$ \\
\hline CILINDRO IMAGEM IMPR OKIDATA MAGENTA & 1 & UN & RS & 713,15 & RS & 713,15 \\
\hline CILINDRO IMAGEM IMPR OKIDATA YELLOW & 7 & UN & RS & 698,23 & RS & $4.887,61$ \\
\hline ESPUMA POLIURETANO VEDAÇÃO E ISOL 400ML & 30 & UN & RS & 13,01 & RS & 390,30 \\
\hline TONER PRETO IMPRESSORA OKIDATA C9600N & 15 & UN & RS & 772,31 & RS & $11.584,65$ \\
\hline TONER CIANO IMPRESSORA OKIDATA C9600N & 6 & UN & RS & $1.165,67$ & RS & $6.994,02$ \\
\hline TONER MAGENTA IMPRESSORA OKIDATA C9600N & 2 & UN & RS & $1.161,74$ & RS & $2.323,48$ \\
\hline TONER PRETO IMPRESSORA OKIDATA C6100N & 12 & UN & RS & 456,66 & RS & $5.479,92$ \\
\hline $\begin{array}{ll} & \text { TOTAL } \\
\end{array}$ & & & & & RS & $50.617,80$ \\
\hline
\end{tabular}

Fonte: Autores

\subsection{Pontos críticos de controle e definição dos indicadores}

Entre todos os processos analisados, os pontos críticos de controle foram identificados no Planejamento dos Estoques, na Aquisição de Bens Móveis e Contratação de Obras e Serviços, no Recebimento de Material no Almoxarifado, na Inspeção de Almoxarifado, no Atendimento de Reserva de Material e na Devolução de Material ao Fornecedor.

No Planejamento dos Estoques, observações in loco e as entrevistas informais revelaram que a principal dificuldade encontrada atualmente está relacionada à carência de informações explícitas, capazes de viabilizar a análise do que será restituído ao armazém. Embora o sistema sugira uma quantidade de reposição, as variáveis que ele utiliza para o cálculo são desconhecidas e, geralmente, o número apresentado não representa a realidade da empresa. Logo, os funcionários realizam análises subjetivas para tomar essas decisões;

Quanto a Aquisição de Bens Móveis e Contratação de Obras e Serviços, a principal adversidade encontrada está relacionada aos atrasos no tempo total de realização deste processo. Por se tratar de uma empresa de economia mista, normalmente a aquisição de bens envolve processos licitatórios, o que às vezes chega a aumentar em 50\% o tempo total de ressuprimento, o que pode gerar rupturas no abastecimento. No Recebimento de Material no Almoxarifado e Devolução de Material ao Fornecedor, os problemas mais comuns estão atrelados aos atrasos na entrega dos fornecedores e a devoluções, ocasionadas no ato do recebimento. Observou-se na Inspeção de Almoxarifado uma carência de informações sobre o tempo de vida útil dos itens. Os funcionários procuram atentar para essa informação, porém a empresa possui uma variedade de mais de 1500 (mil e quinhentos) itens, o que torna inviável ao almoxarife gerenciar manualmente toda essa informação e, assim, perdas, inevitavelmente, acabam ocorrendo.

No processo de Atendimento de Reserva de Material o usuário pertence à mesma unidade onde está situado o almoxarifado e, por meio de uma rotina existente no ERP da empresa, ele cria um documento eletrônico, chamado Reserva de Material (RM), que é analisada e atendida pelo almoxarifado. O documento é, então, impresso, o material é separado e entregue ao requisitante, o qual assina o recebimento. Com esse processo, pode-se avaliar diretamente a satisfação dos usuários 
com o nível de serviço do almoxarifado, surgindo, assim, a necessidade de monitorá-lo para verificar se está funcionando a contento.

Assim, diante das necessidades da empresa, foi proposta uma série de indicadores divididos em dois grupos. O primeiro grupo compreende: nível de serviço, tempo de cobertura do estoque, giro de estoque, consumo dos materiais em estoque, estoque médio, tempo de ressuprimento e o Índice de Materiais Fora da Validade (IMFV). O segundo grupo é constituído por: Índice de Recebimento de Materiais no Prazo (IRMP), Índice de Materiais Disponíveis em Estoque (IMDE), Índice de Requisições de Compra Devolvidas (IRCD), Índice de Reservas Atendidas no Prazo (IRAP) e Índice de Devoluções de Material ao Fornecedor (IDMF). Esse segundo grupo estão relacionados à eficiência dos processos e a sua quantificação independe do tipo de material em análise.

Para os indicadores que necessitam de um mix de análise, optou-se por restringir o escopo do projeto somente aos materiais cuja gestão é de total responsabilidade das pessoas que trabalham no almoxarifado, ou seja, os materiais administrativos, um grupo que atualmente possui 693 itens diferentes.

Para classificar os materiais, foi elaborada uma curva $\mathrm{ABC}$ de demanda valorizada a partir de informação retiradas do software SAP/R3. Como conclusão, os itens do grupo de materiais administrativos apresentaram uma representatividade de 79,96\% na relação custo versus demanda, por esse motivo esse grupo foi escolhido como objeto deste estudo.

A definição dos indicadores de desempenho foi precedida do detalhamento de suas características principais: título, fórmula, objetivo, meta, frequência de medição, frequência de análise, Responsável pela coleta de dados e tratamento dos dados, fonte dos dados, responsável pela análise dos dados e Notas e comentários.

\subsection{Ferramenta computacional desenvolvida para visualização dos indicadores}

Os indicadores Índice de RC Devolvidas e Índice de Devoluções de Materiais ao Fornecedor não puderam ser desenvolvidos com importação automática de dados. Nesse caso foi elaborado um controle manual desenvolvido no Excel, sendo proposto na planilha de RC, o acréscimo de colunas para o preenchimento de dados relacionados a possíveis devoluções tanto de $\mathrm{RC}$ ao almoxarifado para eventuais correções quanto de materiais não conformes aos fornecedores, somadas às informações já existentes, como: número da RC, descrição, data de emissão, data de liberação pelo setor de compras, data de recebimento físico, conforme o apresentado no Quadro 3.

Para o Índice de Materiais Fora da Validade, à proposta foi diferente, realizou-se um mapeamento das rotinas existentes no SAP/R3 e descobriu-se uma rotina capaz de auxiliar neste controle ao assinalar para os usuários os prazos de validade dos materiais, o que permitiria a 
apuração destes dados para criação do indicador no BW SAP, para isso, no momento do recebimento do material o usuário cadastraria no sistema o prazo de validade dos lotes. Entretanto, quando a empresa programou no SAP/R3 está função não estava inclusa no módulo adquirido. A solução proposta foi realizar um levantamento das datas de vencimento dos materiais no armazém, evidenciar os possíveis prejuízos e sugerir a habilitação da função no ERP da empresa para o maior controle.

Quadro 3 - Acompanhamento de RC de estoque, serviços e investimentos do almoxarifado

\begin{tabular}{|c|c|c|}
\hline \multicolumn{3}{|c|}{ ACOMPANHAMENTO DE RC DE ESTOQUE, SERVIÇOS E INVESTIMENTOS DO ALMOXARIFADO } \\
\hline Etapas & $\begin{array}{c}\text { Informaçōes jả existentes no } \\
\text { acompanhamento }\end{array}$ & Informaçōes acrescentadas \\
\hline $\mathrm{RC}$ & $\begin{array}{c}\text { Tipo } \\
\text { Descriçăo } \\
\text { Nümero da RC } \\
\text { Número de itens } \\
\text { Data da emissão }\end{array}$ & $\begin{array}{c}\text { RC foi devolvida ao almoxarifado? } \\
\text { Data da devolução da RC para o almoxarifado } \\
\text { Motivo da devoluçāo da RC } \\
\text { Data de reervio da RC para a àrea de } \\
\text { aquisição }\end{array}$ \\
\hline Carta Contrato & $\begin{array}{c}\text { Contrato } \\
\text { Data de recebimento do email } \\
\text { Previsão de entrega }\end{array}$ & - \\
\hline $\begin{array}{l}\text { Recebimento } \\
\text { do Material }\end{array}$ & $\begin{array}{c}\text { Número da Nota de Recebimento (NR) } \\
\text { Data do recebimento fisico } \\
\text { Observaçōes } \\
\text { Rubrica }\end{array}$ & $\begin{array}{l}\text { Houve devolução de material ao fomecedor? } \\
\qquad \text { Quantidade } \\
\text { Unidade } \\
\text { Motivo da devolução }\end{array}$ \\
\hline
\end{tabular}

Fonte: Autores

\subsection{Alguns exemplos de resultados obtidos com a apuração dos indicadores via BW SAP}

Para exemplificar a aplicação do Sistema de Avaliação de Desempenho, foram selecionados alguns indicadores cadastrados no BW SAP, e apurados seus primeiros resultados. Para os indicadores que necessitavam da definição de um intervalo de tempo para análise, os dados foram coletados durante 10 meses. Para os indicadores que dependiam do tipo de material analisado, foram escolhidos 5 (cinco) itens dos classificados na curva $\mathrm{ABC}$ como mais relevantes para empresa para realização das análises.

O Índice de Materiais Disponíveis em Estoque revelou que dos 693 materiais que deveriam estar disponíveis em estoque, somente 572 possuíam saldo, em outras palavras, 121 materiais apresentam atualmente o saldo igual à zero. Isso significa um percentual de 82,5\%, que está a 14,5 pontos percentuais abaixo da meta de $97 \%$.

O índice de Recebimento de Materiais no Prazo, a partir dos resultados obtidos entre os anos de 2011 e 2012, apresentou os seguintes resultados expressos nas Figuras 2 e 3.

Em 2012, o melhor resultado analisado ocorreu no período de Janeiro, onde o percentual de entregas no prazo foi superior à meta, alcançando o resultado de 95,7\%, enquanto que os piores resultados do ano, até a data da coleta de dados, foram nos meses de Fevereiro e Março, onde, respectivamente, os percentuais foram $39,8 \%$ e 60,4\%, conforme Figura 3. 
Além disso, das 580 entregas recebidas pelo almoxarifado 119 foram fora do prazo, ou seja, o percentual de entregas dentro do prazo foi igual a 79, 5\%. Dos 22 fornecedores que atrasaram no período, 7 tiveram maior significância, atrasando em média cada um 11 entregas. Por fim, o número médio de dias em atraso até a realização da entrega, em 2012, foi igual a 24 dias, sendo que alguns fornecedores chegaram a atrasar em 227 dias o fornecimento de material.

Figura 2 - Indice de recebimento de materiais no prazo em 2011

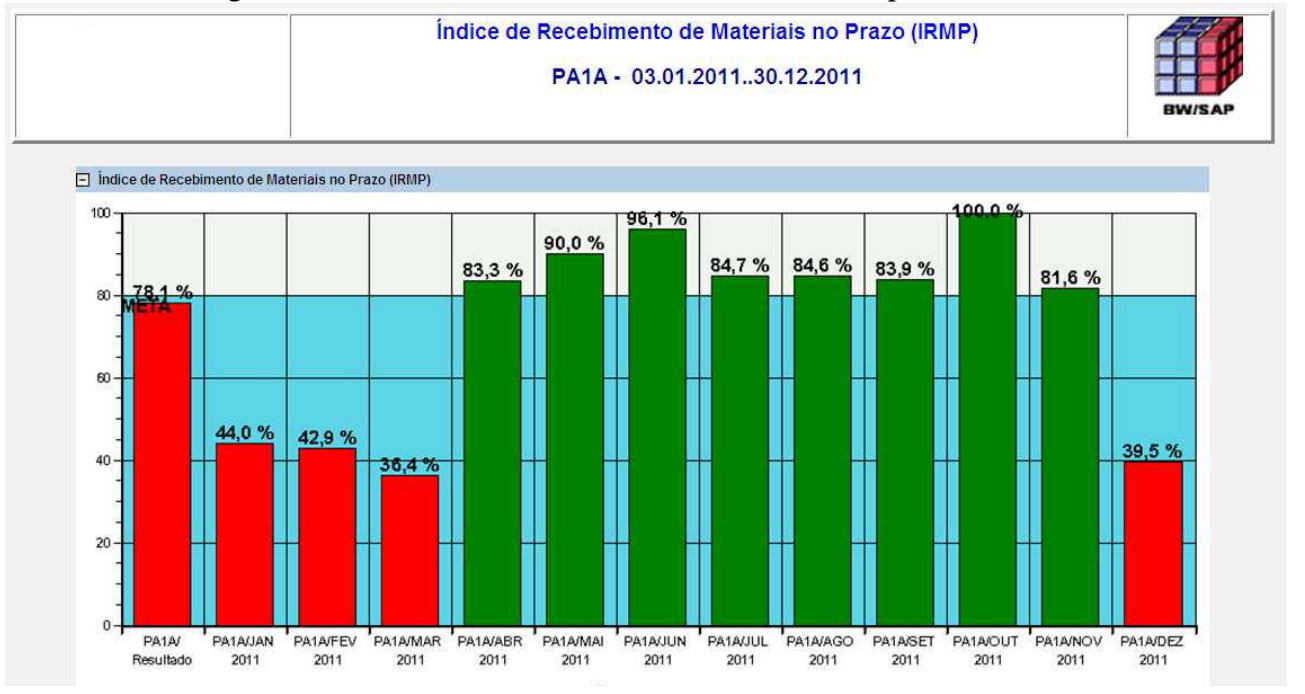

Fonte: Autores

Figura 3 - Indice de recebimento de materiais no prazo em 2012

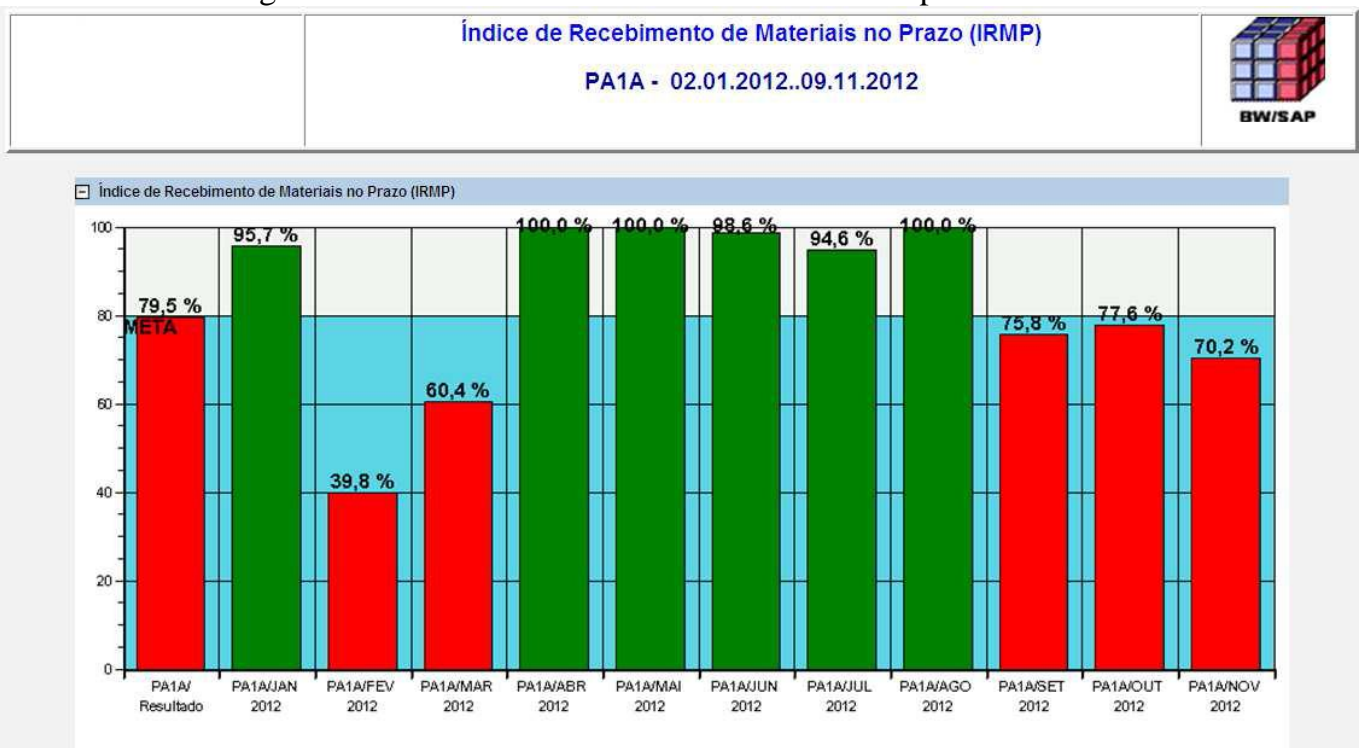

Fonte: Autores

O Índice de Reservas Atendidas no Prazo apresentou os seguintes resultados no período de Janeiro de 2011 a Novembro de 2012:

a) Em nenhum dos meses apurados o almoxarifado conseguiu bater a meta de $95 \%$ de reservas atendidas até um dia útil após a solicitação. Apresentando percentual médio de 
atendimento em 78,27\% e 79,81 nos anos de 2011 e 2012, respectivamente. Os resultados que mais se aproximou da meta ocorreu em Maio de 2011, onde 90\% das reservas foram atendidas no prazo;

b) Segundo os dados de 2011, pode-se inferir que o maior percentual de reservas atendidas após o prazo (19,05\%, equivalente a 40 reservas), foram atendidas em um prazo de três dias. Além disso, houve reservas que chegaram a ser atendidas após mais de 80 dias de sua solicitação, sendo que a reserva 144 atendida mais atrasada no ano foi uma botina de couro preto solicitada no dia 06/01/2011 e atendida em 04/04/2011;

c) Em 2012, o maior percentual de reservas atendidas após o prazo $(15,2 \%$, igual a 31 reservas), foi atendido em três dias. O maior intervalo de tempo de atendimento de reserva após o prazo no ano foi de 274 dias, uma reserva de um pneu radial 245/70/R16 sem câmara, solicitada em 23/11/2011 e atendida em 23/08/2012.

No que diz respeito aos índices que dependem do tipo de material em análise, os itens escolhidos foram: copo plástico descartável de $180 \mathrm{ml}$, papel alcalino branco A-4, cartucho toner Okidata C8800 ciano, bota de segurança condutiva preta $\mathrm{N}^{\circ} 40$ e herbicida capim pós-emergente de 20 litros. Os resultados gerados foram sintetizados nos Quadros 4, 5 e 6.

O cartucho toner Okidata C8800 ciano, a bota de segurança condutiva $\mathrm{n}^{\circ} 40$ e o herbicida capim pós-emergente de 20 litros, não apresentaram demanda em alguns meses do ano de 2011, logo, para esses meses não foram calculados os respectivos percentuais de níveis de serviço, os quais foram representados com um traço (ver Quadro 5).

\begin{tabular}{|c|c|c|c|c|c|c|}
\hline \multicolumn{7}{|c|}{ Nível de Serviço } \\
\hline \multirow[b]{2}{*}{ Ano } & \multirow[b]{2}{*}{ Mês } & \multicolumn{5}{|c|}{ Material } \\
\hline & & $\begin{array}{c}\text { COPO PLÁSTICO } \\
\text { DESCARTÁVEL } \\
180 \mathrm{ml}\end{array}$ & $\begin{array}{c}\text { PAPEL ALCALINO } \\
\text { BRANCA A-4 } \\
75 G / M^{2}\end{array}$ & $\begin{array}{l}\text { CARTUCHO } \\
\text { TONER } \\
\text { OKIDATA } \\
\text { C } 8800 \text { CIANO }\end{array}$ & $\begin{array}{c}\text { BOTA } \\
\text { SEGURANÇA } \\
\text { CONDUTIVA } 40 \\
\text { PRETA }\end{array}$ & $\begin{array}{l}\text { HERBICIDA } \\
\text { CAPIM PÓS- } \\
\text { EMERGENTE } \\
20 L\end{array}$ \\
\hline \multirow{12}{*}{2011} & Jan & $0,10 \%$ & $100,00 \%$ & - & $25,00 \%$ & $13,64 \%$ \\
\hline & Fev & $0,22 \%$ & $96,30 \%$ & - & - & $100,00 \%$ \\
\hline & Mar & $61,58 \%$ & $100,00 \%$ & - & - & $100,00 \%$ \\
\hline & Abr & $0,34 \%$ & $100,00 \%$ & $50,00 \%$ & - & $60,00 \%$ \\
\hline & Mai & $0,55 \%$ & $96,36 \%$ & - & - & - \\
\hline & Jun & $0,25 \%$ & $100,00 \%$ & - & $100,00 \%$ & $66,67 \%$ \\
\hline & Jul & $0,22 \%$ & $100,00 \%$ & - & - & $8,70 \%$ \\
\hline & Ago & $0,76 \%$ & $65,87 \%$ & $100,00 \%$ & - & $100,00 \%$ \\
\hline & Set & $66,53 \%$ & $98,27 \%$ & $100,00 \%$ & - & - \\
\hline & Out & $0,94 \%$ & $71,43 \%$ & - & - & $33,33 \%$ \\
\hline & Nov & $102,46 \%$ & $92,90 \%$ & $100,00 \%$ & $100,00 \%$ & $83,33 \%$ \\
\hline & $\mathrm{Dez}$ & $0,43 \%$ & $33,14 \%$ & - & - & $100,00 \%$ \\
\hline \multicolumn{2}{|c|}{ Média do Período } & $19,53 \%$ & $87,86 \%$ & $87,50 \%$ & $75,00 \%$ & $66,57 \%$ \\
\hline
\end{tabular}

Fonte: Autores 
Diferentemente, da situação encontrada no Quadro 6, onde em alguns meses o nível de serviço para alguns materiais foi igual à zero, ou seja, houve demanda, mas esta não foi suprida, nesses casos preencheu-se a tabela com o valor de $0 \%$ nas células correspondentes.

Quadro 5 - Nível de serviço em 2012 para 5 itens do estoque

\begin{tabular}{|c|c|c|c|c|c|c|}
\hline \multicolumn{7}{|c|}{ Nivel de Serviço } \\
\hline \multirow[b]{2}{*}{ Ano } & \multirow[b]{2}{*}{ Mês } & \multicolumn{5}{|c|}{ Material } \\
\hline & & $\begin{array}{c}\text { COPO PLÁSTICO } \\
\text { DESCARTÁVEL } \\
180 \mathrm{ml}\end{array}$ & $\begin{array}{c}\text { PAPEL ALCALINO } \\
\text { BRANCA A-4 } \\
75 \mathrm{G} / \mathrm{M}^{2}\end{array}$ & $\begin{array}{l}\text { CARTUCHO } \\
\text { TONER } \\
\text { OKIDATA } \\
\text { C } \$ 800 \text { CIANO }\end{array}$ & $\begin{array}{c}\text { BOTA } \\
\text { SEGURANÇA } \\
\text { CONDUTIVA } 40 \\
\text { PRETA }\end{array}$ & $\begin{array}{l}\text { HERBICIDA } \\
\text { CAPIM POS- } \\
\text { EMERGENTE } \\
\text { 20L }\end{array}$ \\
\hline \multirow{12}{*}{2012} & Jan & $101,35 \%$ & $74,36 \%$ & $=$ & $=$ & $0,00 \%$ \\
\hline & Fev & $0,21 \%$ & $91,15 \%$ & $100,00 \%$ & $=$ & $9,09 \%$ \\
\hline & Mar & $97,83 \%$ & $100,00 \%$ & - & - & $33,33 \%$ \\
\hline & Abr & $0,94 \%$ & $100,00 \%$ & $=$ & $=$ & $85,71 \%$ \\
\hline & Mai & $99,14 \%$ & $95,96 \%$ & - & $0,00 \%$ & $100,00 \%$ \\
\hline & Jun & $1,64 \%$ & $94,68 \%$ & $100,00 \%$ & $0,00 \%$ & $100,00 \%$ \\
\hline & Jul & $0,32 \%$ & $100,00 \%$ & - & $100,00 \%$ & $50,00 \%$ \\
\hline & Ago & $0,19 \%$ & $100,00 \%$ & - & - & $100,00 \%$ \\
\hline & Set & $0,18 \%$ & $8,62 \%$ & $100,00 \%$ & - & $83,33 \%$ \\
\hline & Out & $95,65 \%$ & $13,28 \%$ & - & - & $100,00 \%$ \\
\hline & Nov & $101,56 \%$ & $100,00 \%$ & - & - & - \\
\hline & Dez & - & - & - & - & $=$ \\
\hline \multicolumn{2}{|c|}{ Média do Período } & $45,36 \%$ & $79,82 \%$ & $100,00 \%$ & $33,33 \%$ & $66,15 \%$ \\
\hline
\end{tabular}

Fonte: Autores

De acordo com o Quadro 6, percebe-se que em 2011 não houve aquisição de herbicida, e, em 2012, não houve aquisição do cartucho, da bota de segurança e do herbicida.

Quadro 6 - Indicadores de desempenho do estoque

\begin{tabular}{|c|c|c|c|c|c|c|}
\hline \multirow[b]{2}{*}{ Ano } & \multirow[b]{2}{*}{ Indicador } & \multicolumn{5}{|c|}{ Material } \\
\hline & & $\begin{array}{c}\text { Copo } \\
\text { Plástico } \\
\text { Descartável } \\
180 \mathrm{ml} \text { (MIL) }\end{array}$ & $\begin{array}{c}\text { Papel } \\
\text { Alcalino } \\
\text { Branco A-4 } \\
75 \mathrm{G}^{\prime} \mathrm{M}^{2} \text { (RS) }\end{array}$ & $\begin{array}{c}\text { Cartucho } \\
\text { Tonner } \\
\text { Okidata } \\
\text { C8800 Ciano } \\
\text { (UN) }\end{array}$ & $\begin{array}{c}\text { Bota } \\
\text { Segurança } \\
\text { Condutiva } \\
\text { 40 PRreta } \\
\text { (PAR) }\end{array}$ & $\begin{array}{l}\text { Herbicida } \\
\text { Capim Pós } \\
\text { emergente } \\
20 \mathrm{~L} \text { (UN) }\end{array}$ \\
\hline 2011-2012 & Tempo de Cobertura (dias) & 200 & 149 & 817 & 1700 & 27 \\
\hline 2011 & $\begin{array}{l}\text { Tempo de Ressuprimento Médio } \\
\text { (dias) }\end{array}$ & 109 & 31,5 & 47 & 153 & - \\
\hline 2012 & $\begin{array}{l}\text { Tempo de Ressuprimento Médio } \\
\text { (dias) }\end{array}$ & 72 & 112 & - & - & - \\
\hline 2011 & Giro de Estoque & 3,3 & 5,2 & 0,4 & 0,0 & 0,7 \\
\hline 2012 & Giro de Estoque & 1,5 & 2,5 & 0,4 & 0,3 & 1,8 \\
\hline 2011 & Estoque Médio Mensal & 394,6 & 448,8 & 63,2 & 3,5 & 75,1 \\
\hline 2012 & Estoque Médio Mensal & 868,7 & 962,4 & 55,0 & 20,5 & 26,2 \\
\hline 2011 & Consumo Médio Mensal & 108,5 & 165,7 & 1,8 & 0,3 & 4,7 \\
\hline 2012 & Consumo Médio Mensal & 115,5 & 216,5 & 1,7 & 0,6 & 4,8 \\
\hline 2012 & Estoque atual & 754,5 & 1035,0 & 49,0 & 17,0 & 4,0 \\
\hline 2012 & Ponto de Ressuprimento & 515,0 & 1055,0 & 16,3 & 12,0 & 25,4 \\
\hline
\end{tabular}

Fonte: Autores

Portanto, como esses são itens que possuem a frequência de compra inferior aos demais e, para analisar seu tempo de ressuprimento $\left(T_{R}\right)$, era necessário que houvesse amostras de pelo menos dois anos, então se calculou o indicador puxando dados de anos anteriores ao período estabelecido 
de análise. Para o cartucho, o $T_{R}$ médio foi de 47 dias. Para a bota de segurança, o $T_{R}$ médio foi 145 dias. E, por fim, o herbicida, que não foi adquirido nem em 2011 e nem em 2012, foi comprado pelas últimas vezes em 2009 e 2010, apresentando, respectivamente, os valores de 247 e 134 dias de $\mathrm{T}_{\mathrm{R}}$ médio nos períodos.

\section{Análise dos resultados}

De acordo com os primeiros resultados apurados, após a implementação dos indicadores, é possível fazer uma análise preliminar sobre a situação presente do almoxarifado central da empresa. No que diz respeito aos indicadores que não puderam ser implementados no BW SAP, Índice de RC Devolvidas e Índice de Devoluções de Materiais ao Fornecedor, não foi possível a realização de uma análise mais consistente, pois os dados de ambos começaram a ser coletados em setembro de 2012 e não havia na empresa um banco de dados com histórico das informações necessárias para a análise desses indicadores.

Sobre o Índice de Materiais Fora da Validade, verificou-se que a falta de monitoramento do tempo de vida útil dos materiais já causou perdas financeiras para empresa de exatos $\mathrm{R} \$ 146.718$, 38 (Cento e quarenta e seis mil, setecentos e dezoito reais e trinta e oito centavos), somente no levantamento realizado nos últimos dois anos (2011 e 2012), nos itens de classe A, o que representa não só uma perda monetária para a empresa, mas como um custo de falta de material, podendo prejudicar o funcionamento das outras áreas da empresa que dependem dos materiais que estão indisponíveis para uso.

Ao analisar o Índice de Materiais Disponíveis em Estoque, percebe-se que o baixo desempenho atual do almoxarifado, neste índice em relação à meta, pode estar diretamente ligado ao desempenho de outro índice calculado, o Índice de Recebimento de Materiais no Prazo (IRMP). Observou-se na análise dos resultados dos dois últimos anos que, para o IRMP, o melhor desempenho dos fornecedores se concentra no meio do ano, basicamente entre Abril e Agosto. Por exemplo, em 2011, das 120 entregas fora do prazo, aproximadamente 50\% (59 recebimentos) foram em Janeiro, Fevereiro e Dezembro e, em 2012, das 119 entregas atrasadas, 91 recebimentos (aprox. $76,47 \%$ do total de atrasos do período) foram nos meses de Janeiro, Fevereiro e Novembro.

Diante deste resultado, em uma análise preliminar, pode-se inferir que os fornecedores possuem maior dificuldade de entregar esses itens no início e no término do período anual, que são justamente os períodos que a maioria das empresas tende a solicitar estes materiais.

Avaliando o Índice de Reservas Atendidas no Prazo de 2011 e 2012, percebe-se que o desempenho do almoxarifado está aquém da meta estabelecida em todos os períodos de análise, sendo maio de 2011 o período que o resultado mais se aproximou da meta, ainda sim ficando 5 pontos percentuais abaixo da meta de $95 \%$. De acordo com a observação in loco, pode-se inferir que 
quando o atraso é inferior a 1 (um) mês, na maioria dos casos, este cenário pode ser justificado pelo fato de que, atualmente, a equipe conta somente com um auxiliar de serviços gerais que é responsável pela realização das entregas dos materiais aos usuários.

\section{Considerações finais}

A gestão por indicadores, aqui proposta, foi elaborada inicialmente para funcionar no almoxarifado central de uma das unidades da empresa, porém, a partir dos resultados que serão obtidos nos primeiros anos de uso, pretende-se disseminá-lo às demais unidades.

O presente artigo atingiu seu objetivo principal, o de propor uma metodologia para o desenvolvimento de um sistema de avaliação de desempenho da gestão do estoque em uma empresa do setor elétrico. Nesse caso, a metodologia partiu do pleno entendimento das atividades envolvidas no processo de produção de energia elétrica. A partir da compreensão do processo, foram identificados os pontos críticos para a gestão e definidos indicadores de desempenho voltados para interesse estratégico da empresa, tarefas realisadas com o apoio dos funcionários responsáveis por cada uma dessas atividades.

A partir da implementação do SAD no Almoxarifado da empresa foi possível fazer uma análise preliminar dos resultados obtidos. Como resultado, os indicadores apontaram os elementos falhos na gestão do estoque, possibilitando uma relação com os impactos no nível de serviço e na e aumento nos custos da empresa. Para trabalhos futuros, sugere-se analisar também os impactos das decisões do componente gestão de estoques nos demais componentes operacionais de desempenho logísticos (instalações e transporte), considerando também os desempenhos estratégicos (custos e nível de serviço). Além disso, muitos parâmetros definidos no projeto foram estabelecidos com base na experiência dos funcionários da área, portanto, outro ponto a ser explorado seria o desenvolvimento de um estudo estatístico para definição dos critérios de análise.

\section{Abstract}

This paper presents a methodology for the establishment of a Performance Evaluation System of Inventory Management based on logistics indicators. To this end, a pilot project to be implemented at the central warehouse of an electrical company, located in Pará was prepared. Definition of performance indicators for this situation was made from the mapping of processes and subsequent identification of critical processes through the strategic vision of the company. Then the inventory items have been defined for the pilot project, which was based on a computational tool for the collection and automatic processing of data as well as the visualization of performance indicators. From the initial results, it was possible to measure the performance of the warehouse processes considering the indicators to be improved. Thus, it became evident the potential use of the proposed continuous improvement in the Inventory Management system of activities.

Keywords: performance indicators; materials management; inventory management; electrical industry. 


\section{Referências}

AGÊNCIA NACIONAL DE ENERGIA ELÉTRICA - ANNEL. Atlas de energia elétrica do Brasil / Agência Nacional de Energia Elétrica. 3. ed. Brasília: Aneel, 2008. Disponível em: 〈http://www.aneel.gov.br/arquivos/PDF/atlas3ed.pdf>. Acesso em: 26 fev. 2012.

BALLOU, R. H. Gerenciamento da cadeia de suprimentos: planejamento, organização e logística empresarial. $4^{\mathrm{a}}$ ed. Porto Alegre: Bookman, 2001.

BertagliA, P. R. Logística e Gerenciamento da Cadeia de Abastecimento. $2^{\text {a }}$ Ed. rev. e atual. - São Paulo: Saraiva, 2009.

BOWERSOX, D. J.; CLOSS, D.; COOPER, M. Gestão da Cadeia de Suprimentos e Logística. $2^{\mathrm{a}}$ ed. Rio de Janeiro: Elsevier, 2007.

CHIAVENATO, I. Administração de produção: uma abordagem introdutória. Rio de Janeiro: Elsevier - $10^{\mathrm{a}}$ Reimpressão, 2005.

DAVIS, M. M.; AQUILANO, N. J.; CHASE, R. B. Fundamentos da administração da produção. 3.ed. Porto Alegre, RS: Bookman, 2001. xii, 598 p. ISBN 8573075244 (enc.), 2001.

FUNDAÇÃO NACIONAL DA QUALIDADE (FNQ). Caderno de excelência: resultados. Série cadernos de excelência. NNo $^{\circ}$. ISBN 978-85-60362-57-8, São Paulo, 2008. Disponível em:

<http://pt.scribd.com/doc/7469485/Caderno Excelência- 2008-Vol-08-Resultados〉. Acesso: 06 mai. 2012.

GUNASEKARAN, A.; PATEL, C.; TIRTIROGLU, E. Performance measures and metrics in a supply chain environment. International Journal of Operations \& Production Management, v. 21, n. 1-2, p. 71-87, 2001. crossref

JACOBSEN, M. Logística Empresarial. 2ª ed. rev. e ampl. Universidade do Vale do Itajaí, Itajaí, 2006.

KAPLAN, R. S.; NORTON, D. P. Using the Balanced Scorecard as a Strategic Management System. 2007. 15p. Disponível em: <http://hbr.org/2007/07/using-thebalanced- scorecard-as-a-strategic-management-system/ar/1>. Acesso em: 07 mai. 2012.

LIMA, R. H. P. Desenvolvimento e aplicação de uma ferramenta de medição de desempenho em indústrias de bens de capital. 2008. 195p. Dissertação (Mestrado) - Escola de Engenharia de São Carlos, Universidade de São Paulo, São Carlos, 2008.

MARTINS, P. G.; ALT, P. R. C. Administração de materiais e recursos patrimoniais. $3^{\text {a }}$ ed. rev. e atualizada. - São Paulo: Saraiva, 2009.

MELO, A. C. S. Logística e Integração Empresarial: Logística, 1-31 de ago. de 2011. Notas de Aula.

MELO, A. C. S. Uma Estrutura de análise de Operações Destinada à Melhoria de Processos do Transporte de Cargas Excepcionais Indivisíveis. 142p. Tese de D. Sc., Engenharia de Produção, COPPE/UFRJ, Rio de Janeiro, Brasil, 2006.

MOREIRA, D. A. Administração da produção e operações. 2a ed. ver. e ampl. São Paulo: Cengage Learning, 2009. Plano Decenal de Expansão de Energia 2020-PDE / Ministério de Minas e Energia. Empresa de Pesquisa Energética. Brasília: MME/EPE, 2011. 2 v.: il. Disponível em:< http://www.epe.gov.br/PDEE/Forms/EPEEstudo.aspx >. Acesso em: 01 mar. 2012.

NOVAES, A. G. Logística e gerenciamento da cadeia de distribuição. 2. Ed. - 4ª reimpr. - Rio de Janeiro: Elsevier, 2007.

RENTES, A.; CARPINETTI, L.; AKEN, V. Measurement system development process: a pilot application and recomendations. Artigo publicado nos Anais do PMA Conference. Boston: [s.n.], 2002.

SILVA. R. F. Indicadores de eficiência e eficácia: uma visão prática sobre os indicadores de desempenho para avaliar a eficiência e a eficácia dos processos organizacionais. 2007. 11p. Qualypro Tecnologia. Disponível em: <http://www.qualypro.com.br/novosite/outros_artigos.asp?id=27>. Acesso em: 06 mai. 2012. 


\section{Dados dos autores}

\section{Nome: Nayáry Pinheiro Monteiro}

Filiação Institucional: Universidade do Estado do Pará, UEPA

Função ou cargo: Engenheira de Produção

Endereço completo para correspondência: Travessa Enéas Pinheiro, 2626. Belém - PA - Brasil

Telefone para contato: (55) 91 3276-4011/3131-1907

e-mail: narypinheiro@gmail.com

\section{Nome: André Cristiano Silva Melo}

Filiação Institucional: Universidade do Estado do Pará, UEPA

Função ou cargo: Professor D.Sc. em Engenharia de Produção, e Coordenador dos laboratórios CONCEPT E NILO

Endereço completo para correspondência: Travessa Enéas Pinheiro, 2626. Belém - Pa. Brasil

Telefone para contato: (55) 91 3276-4011/3131-1907

e-mail: acsmelo@yahoo.com.br

\section{Nome: Denilson Ricardo de Lucena Nunes}

Filiação Institucional: Universidade do Estado do Pará, UEPA

Função ou cargo: Professor D.Sc. em Engenharia de Produção

Endereço completo para correspondência: Travessa Enéas Pinheiro, 2626. Belém - Pa. Brasil

Telefone para contato: (55) 91 3276-4011/3131-1907

e-mail: denilson.lucena@ibest.com.br

Submetido em: 29/09/2014

Aceito em: 17/12/2014 